\title{
Soil Fertilization of SARRACENIA SeEdlings
}

JOHN BRITTNACHER • Ashland, Oregon • USA・john@ carnivorousplants.org

Keywords: cultivation: fertilizers, Sarracenia.

Conventional wisdom has it that soil fertilization is dangerous for carnivorous plants. A grower may get away with it once or twice with great results but the next time wipe out their whole collection. I have seen this on a small scale with volunteers at the University of California, Davis, Botanical Conservatory multiple times. At first the plants are truly stunning. Give them one treatment too many or at the wrong time and all the plants die. We are talking hundreds of plants.

Foliar fertilization with foliar fertilizer at a quarter to half of the label-recommended strength is what is generally recommended (D'Amato 1997, 1998a; Rice 2006), although Hanrahan (1986) recommends more dilute fertilizer used much more often. In fact, in general horticulture foliar fertilization is quite commonly recommended because plants are well adapted to absorbing nutrients on their leaves, especially carnivorous plants. But then there is the curious article by Peter D'Amato (D'Amato 1998b) about killing his Mexican Pinguicula while foliar fertilizing Sarracenia using a half-recommended-strength fertilizer solution in a watering can. Using a watering can results in more than foliar feeding! I mist Mexican Pinguicula with the same fertilizer at the same strength all the time with excellent results. This is starting to sound like soil fertilization.

What motivated me to do the experiments reported here was the success I had with heavy foliar feeding of the Sarracenia rubra subsp. alabamensis plants used for the ICPS distribution (Rice 2003). It was not exactly watering-can foliar feeding, but it was heavy enough to cause some algae and moss problems on the soil. Sarracenia rubra are notoriously slow growers and tend to stay small and clumpy for a long time. I had a deadline. The plants appeared to appreciate the fertilizer.

In trials I did in a terrarium at home I found that soil fertilization of Dionaea and Sarracenia seedlings was of little if any value. I think this is a result of the excessive moss growth, possibly reactions with the soil in stagnant terrarium conditions, and not enough light for the plants to effectively use the extra nutrients. But I was able to use much more fertilizer without killing any plants than I would have expected.

For the actual experiments I first wanted to do a trial determining the best level of fertilizer in a production system with the plants under the excellent greenhouse conditions available at UC Davis. I was growing a lot of Sarracenia for collections enhancement and new hybrid selections. I used a relatively low nitrogen fertilizer for this trial, thinking that nitrogen was not as important as phosphorus. A trial was then performed with different fertilizer formulations to see what the plants responded to best. I used a high-nitrogen fertilizer and a very high phosphorus fertilizer in addition to the balanced formulation.

Except for the high-phosphorus treatment, I used slow-release pellet ("prill") fertilizers. I wanted to avoid a system of periodic soil drenches as there are more likely to be errors and timing issues with that kind of a system. In addition, acidic soils generally pass nutrients directly through, so the plants would be alternating between high nutrients and low nutrients. The pellets should give a more uniform nutrient environment. It was not practical to add fertilizer to the water used for the carnivorous plants. That would probably be more common in a commercial growing situation where there are enough Sarracenia to justify a separate water system. The pellets have a plastic coating that should release the fertilizer slowly over a long period of time, keeping the nutrient levels constant. I felt that as long as the slow-release pellets were above the water level in the trays they would work as they were supposed to. 
Three fertilizer trials were performed to test the effects of soil fertilization on the growth of seedling Sarracenia. The first trial tested the effect of the quantity of fertilizer used. The other trials tested the effect of using different fertilizer formulations. Each trial was initiated in the spring with one-year-old seedlings and lasted approximately 14 to 18 months. The plants were grown in a controlled-environment greenhouse at the University of California, Davis, along with other carnivorous plants being grown for collections enhancement, and received similar care that included occasional top watering and foliar feeding.

For all the trials, seedlings were transplanted into $56-\mathrm{mm}$ wide by $85-\mathrm{mm}$ tall "rose" pots. The pots had been filled with 1:1 peat:sand soil. Fertilizer pellets were placed about $1 \mathrm{~cm}$ below the surface of the soil. The pots were put into standard $27-\mathrm{cm}$ by $54-\mathrm{cm}$ wide, $6-\mathrm{cm}$ deep plant trays with holes punched about $2 \mathrm{~cm}$ up the sides to keep the water level below the fertilizer pellets in the pots. The fertilizer pellets were individually selected so that a certain number of typical pellets were used per pot. The plants were then placed into a greenhouse with bright light yearround and heating and cooling. The trays were checked for water level daily and refilled with RO water as necessary. Occasionally the plants were top watered, the trays were dumped for cleaning, and the plants received foliar fertilizer.

Trial 1 consisted of 36 pots of Sarracenia seedlings. At the time we thought the seedlings were $S$. oreophila $\times$ flava var. atropurpurea-we wanted to use simple hybrid seedlings because of prior observations that simple hybrids generally had more uniform offspring than either complex hybrids or seed from cultivated pure species. However, we later learned that the "S. flava" parent was actually itself a plant of uncertain hybrid origin. Nine pots each had zero, 2, 4, or 6 pellets of Osmocote ${ }^{\mathrm{TM}}$ 14-14-14 Vegetable \& Bedding formula 4-month-release fertilizer pellets. The maximum of 6 pellets was chosen as that is about the amount that would be used for non-carnivorous plants grown in that size pot. After 14 months, Conservatory propagation volunteers were asked to divide the plants into as many groups as they felt comfortable based on size and general health of the plant. The tags were turned so they could not be read during scoring. The volunteers opted to divide the plants into two groups: a score of "1" was given to the group with larger plants, " 0 " to the group with smaller plants. Minimum group size for scoring was five to conform to the requirements of statistical analysis by the $\chi^{2}$ test.

Trial 2 consisted of 72 pots of a hybrid Sarracenia flava var. rubricorpora by the complex hybrid used in the cross for Trial 1. Eighteen pots each had no pellets, 4 Osmocote ${ }^{\mathrm{TM}} 14-14-14$ Vegetable \& Bedding formula 4-month-release fertilizer pellets, 4 Osmocote ${ }^{\mathrm{TM}}$ 17-7-12 commercial 12- to 14-month-release fertilizer pellets (this exact formulation is no longer available, but similar formulations are available in their Classic product line for commercial growers), or 4 double superphosphate 0-40-0 granules about the size of the Osmocote ${ }^{\mathrm{TM}}$ pellets (after it was too late it was discovered these were double superphosphate instead of regular superphosphate as intended). The author scored the plants at the end of the trial based on the same criteria as Trial 1 . The plants were divided into four groups with higher scores given to the larger-sized plants.

Trial 3 consisted of 27 seedlings from a cultivated Sarracenia leucophylla, Wilkerson Bog,

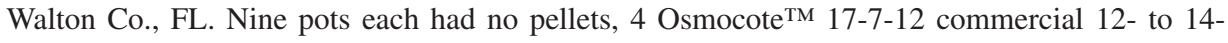
month-release fertilizer pellets, or 4 double superphosphate $0-40-0$ granules. The author scored the plants at the end of the trial based on the same criteria as Trial 1. The plants were divided into three groups with higher scores given to the larger-sized plants.

\section{Results}

The first fertilizer trial testing the effects of the level of a balanced slow-release fertilizer showed that the use of the fertilizer in the soil was quite advantageous to the plants (see Table 1 and Figure $1)$. There were no fatalities. All treatments gave results that were statistically different using $\chi^{2}$ tests $(\mathrm{p}<0.05)$ and with larger plants than the "no fertilizer" control. The 4- and 6-pellet treat- 
ments gave the same results, and those treatments were statistically different $(\mathrm{p}<0.05)$ with larger plants than the 2-pellet treatment. The surprising result was not so much that the leaves were larger but that the rhizomes were huge for plants of that age (see Figure 2). Rhizome size was not measured, as to do so would have damaged the plants too much.

An interesting side note is that although the treated plants achieved apparent blooming size a year early, they did not produce inflorescences. This was also observed in plants not part of this trial. Additional experiments would have to be performed to confirm this was not simply a seasonal timing issue or a result of being under greenhouse conditions.

The results of Trials 2 and 3 indicated that nitrogen fertilizer level was a key element for the plants (see Tables 2 and 3 and Figure 3). There were two fatalities apparently unrelated to treatment, so they were ignored in the analysis. The double-superphosphate treatment plants in Trial 2 were statistically different using a $\chi^{2}$ test $(\mathrm{p}=0.05)$ and smaller than the controls; in Trial 3 they were not statistically different from the controls $(\mathrm{p}=0.64)$. The slow-release fertilizer treatment plants were statistically different using $\chi^{2}$ tests $(\mathrm{p}<0.05)$ and larger than the controls and the double-superphosphate treatment plants. The higher nitrogen treatment was statistically different $(\mathrm{p}=$ 0.0008) from and the plants larger than the balanced formulation plants.

\section{Discussion}

These experiments indicate that under controlled greenhouse growing conditions Sarracenia seedlings benefit greatly from the use of soil fertilization with pelleted slow-release fertilizer. Although not used in these tests, the fertilizer I would use from now on for seedlings grown in a greenhouse or outdoors is Osmocote ${ }^{\text {TM }}$ 19-6-12 4-month Outdoor \& Indoor Smart Release ${ }^{\circledR}$ Plant Food. It is readily available, and in my tests putting the pellets into water and measuring conductivity with a TDS meter, it releases nutrients into the water more slowly than the 17-7-12 pellets used in the experiments reported here. The 17-7-12 pellets used were old, the plastic coating may have broken down somewhat, and the manufacturing process used when they were made may not be representative of any available now.

Soil fertilization could cause more problems than it is worth if the Sarracenia plants are not grown under enough light and in warm conditions. I hesitated publishing this paper because I was afraid I might encourage novice growers to over-fertilize their plants, killing or stunting them. Even at the UC Davis Botanical Conservatory where the experiments were conducted we do not routinely use these treatments for seedling Sarracenia-yet. We never experiment with all our plants. When we do experiment, we always use multiple plants for the control as well as for the experimental plants. If you do not have control plants to see what would have happened if you had done nothing different, you will not know what would have happened if you had done nothing. If you fertilize the one plant you have and it does spectacularly (or dies) all of a sudden, you do not know if it was the fertilizer or the cat. We are now checking to see if the treatments are safe for various pure species.

Availability of fertilizer to plant roots is very much dependent on soil conditions. Low $\mathrm{pH}$ soils like typical peat:sand mixes used by many growers have lower nutrient availability than soil mixes containing more neutral $\mathrm{pH}$ ingredients like coco coir. Substitution of chopped sphagnum moss or perlite or more or less sand could also affect availability. I would be wary of using these techniques with Sarracenia species that normally live on floating sphagnum mats such as $S$. purpurea subsp. purpurea and S. minor var. okefenokeensis since they would not normally experience the potentially high nutrients or salts in boggy soils. However, the other species probably experience relatively high nutrients, or at least salts, during periods of low precipitation in the wild and are thus somewhat pre-adapted to conditions they would experience with fertilizer as long as the water and soils used in the nursery are sufficiently low in other nutrients and salts.

It would require more experiments to determine the safe and effective levels of soil fertilization for juvenile and adult Sarracenia. I suspect that older plants of most species and hybrids would tolerate quite high levels of fertilizer. Because of their yearly growth cycles, in 


\begin{tabular}{|c|c|c|}
\hline \multicolumn{3}{|c|}{ RESULTS OF TRIAL 1 } \\
\hline $\begin{array}{c}\text { Number of } \\
\text { Pellets }\end{array}$ & 0 & 1 \\
\cline { 2 - 3 } & 9 & 0 \\
\hline $0^{\mathrm{a}}$ & 5 & 4 \\
\hline $2^{\mathrm{b}}$ & 1 & 8 \\
\hline $4^{\mathrm{c}}$ & 1 & 8 \\
\hline $6^{\mathrm{c}}$ & & \\
\hline
\end{tabular}

Table 1: Effects of different numbers of Osmocote ${ }^{\text {TM }}$ 14-14-14 Vegetable \& Bedding formula 4-month release fertilizer pellets per pot. For scoring, the plants were sorted into groups of similar size and health. The higher the score the larger and more healthy the plants in the group were judged to be. a,b,cGroups with same superscript are not significantly different $(p<0.05)$.

\begin{tabular}{|c|c|c|c|c|}
\hline \multicolumn{5}{|c|}{ RESULTS OF TRIAL 2 } \\
\hline \multirow{2}{*}{$\begin{array}{c}\text { Type of } \\
\text { Pellets }\end{array}$} & 0 & 1 & 2 & 3 \\
\cline { 2 - 5 } & 6 & 12 & 0 & 0 \\
\hline none $^{\mathrm{a}}$ & 12 & 6 & 0 & 0 \\
\hline $0-40-0^{\mathrm{b}}$ & 0 & 6 & 9 & 3 \\
\hline $14-14-14^{\mathrm{c}}$ & 0 & 0 & 4 & 13 \\
\hline $17-7-12^{\mathrm{d}}$ & 6 & \multicolumn{4}{|c|}{ Score } \\
\hline
\end{tabular}

Table 2: Effects of Osmocote ${ }^{\mathrm{TM}}$ 14-14-14 Vegetable \& Bedding formula 4 month release fertilizer pellets, Osmocote ${ }^{\mathrm{TM}}$ 17-7-12 commercial 12-14 month release fertilizer pellets, and double superphosphate 0-40-0 granules. For scoring, the plants were sorted into groups of similar size and health. The higher the score the larger and more healthy the plants in the group were judged to be. Groups with same superscript are not significantly different $(p<0.05)$.

\begin{tabular}{|c|c|c|c|}
\hline \multicolumn{4}{|c|}{ RESULTS OF TRIAL 3 } \\
\hline $\begin{array}{c}\text { Type of } \\
\text { Pellets }\end{array}$ & 0 & 1 & 2 \\
\cline { 2 - 4 } & 2 & 6 & 1 \\
\hline none $^{\mathrm{a}}$ & 2 & 4 & 2 \\
\hline $0-40-0^{\mathrm{a}}$ & 0 & 2 & 7 \\
\hline $17-7-12^{\mathrm{b}}$ & & & \multicolumn{2}{|c|}{ Score } \\
\hline
\end{tabular}

Table 3: Effects of Osmocote ${ }^{\mathrm{TM}}$ 17-7-12 commercial 12-14 month release fertilizer pellets and double superphosphate 0-40-0 granules. For scoring, the plants were sorted into groups of similar size and health. The higher the score the larger and more healthy the plants in the group were judged to be. ${ }^{a, b}$ Groups with same superscript are not significantly different $(p<0.05)$. 
Figure 1:

Plants from Trial 1 with different numbers of Osmocote ${ }^{\mathrm{TM}}$ 14-14-14 Vegetable \& Bedding formula 4-month-release fertilizer pellets per pot.
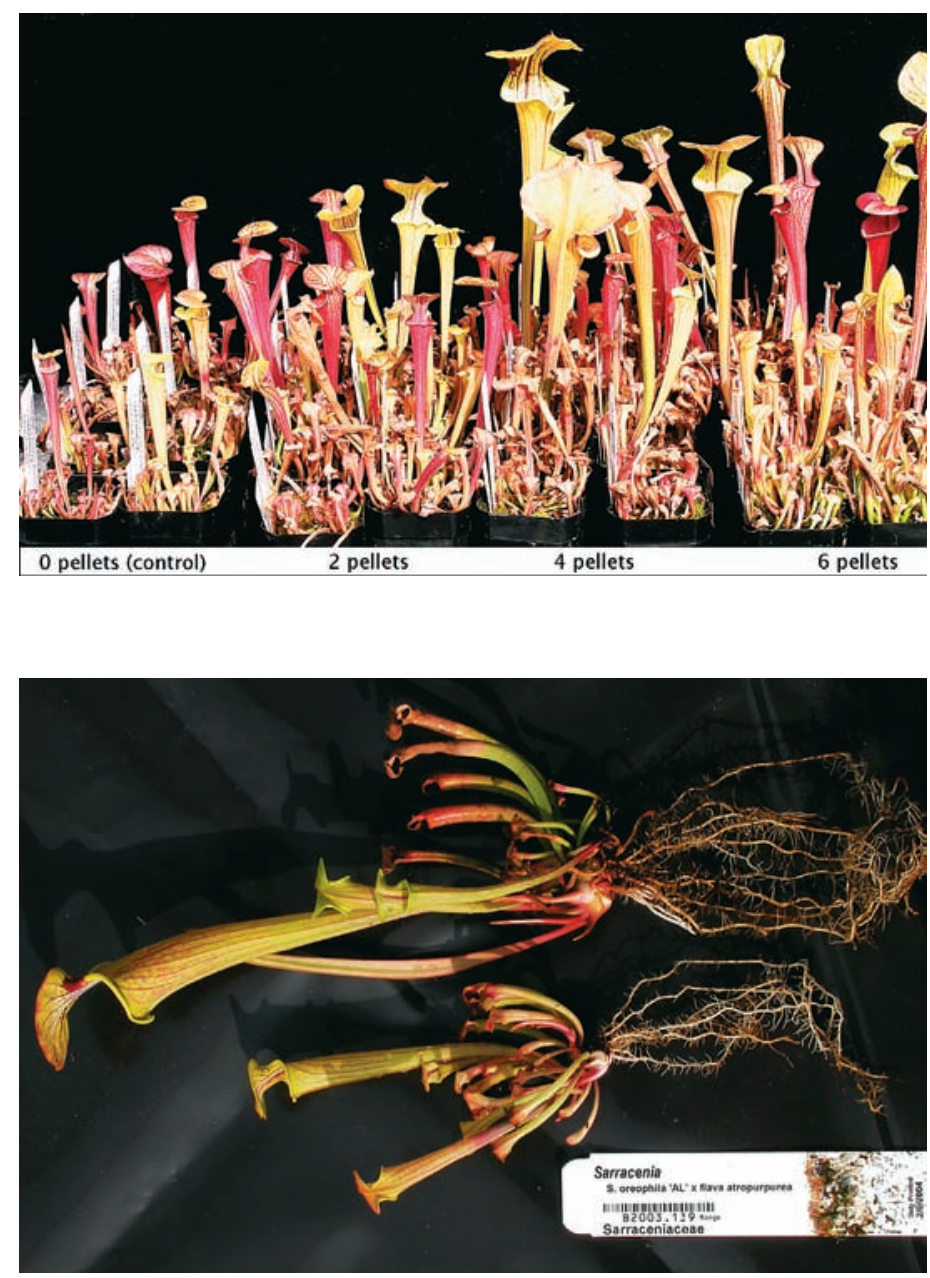

Figure 2:

Comparison of plants from Trial 1 with a typical control plant on the bottom and a plant typical of those with 4 or 6 pellets on the top. Note the larger rhizome on the plant on the top. The name tag is erroneous, as described in the text.

Figure 3:

Plants from Trial 3 with 4 double superphosphate 0-40-0 granules and 4 Osmocote $^{\mathrm{TM}}$ 17-7-12 commercial 12- to 14month-release fertilizer pellets.

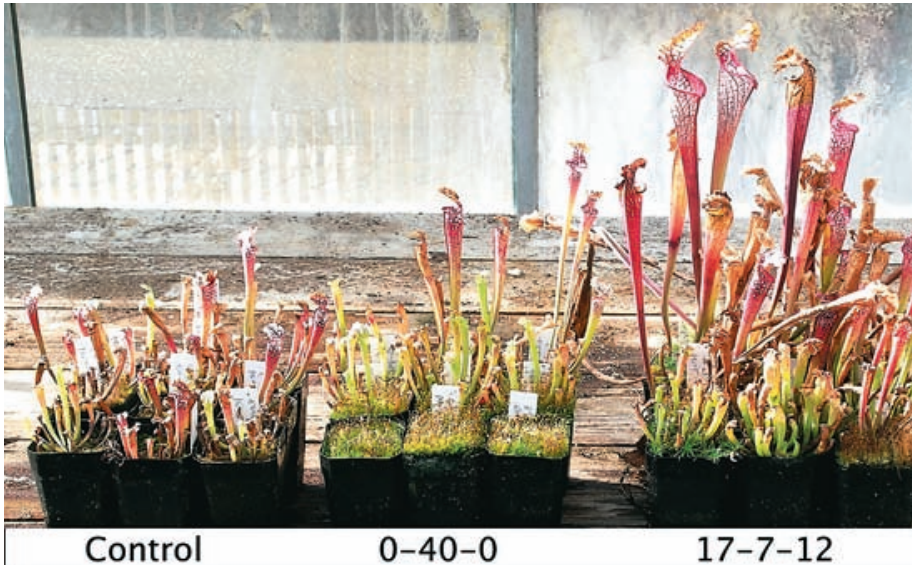


order for fertilization to be effective the timing would be critical and other growth conditions such as lighting should be optimal. The leaves may burn or become deformed at high levels, but if the purpose is to grow the plants as quickly as possible, that may be a small price to pay.

I have found the Osmocote ${ }^{\mathrm{TM}}$ pellets to be useful with other genera than Sarracenia. Largescale commercial growers undoubtedly have fertilizer regimes that work well for them. For hobby growers the pellets are quite handy. I feed seedling Nepenthes and Cephalotus in their pitchers with dried blood worms. At about the point the plants can take a large pinch of blood worms I switch to Osmocote ${ }^{\mathrm{TM}}$ pellets. I only use one pellet in one pitcher in each plant and then wait to see what happens. The plants need to already be doing very well or the pitcher and possibly the plant could be killed. That usually means there is a lot of water in the pitchers. Be careful because over-fertilization of Nepenthes could cause them to grow too well and to stop producing pitchers. If your Nepenthes suddenly grow like crazy but don't produce pitchers, cut them back and use the excess growth for stem cuttings.

Acknowledgements: I thank Tim Metcalf, Ernesto Sandoval, Doug Walker, and interns and volunteers at the University of California, Davis, Botanical Conservatory for the space and assistance required to do these experiments.

\author{
References \\ D’Amato, P. 1997. The Savage Garden. Carniv. Pl. Newslett. 26: 64-66. \\ D’Amato, P. 1998a. The Savage Garden. Ten Speed Press, Berkeley. \\ D'Amato, P. 1998b. The Savage Garden. Carniv. Pl. Newslett. 27: 100-101. \\ Hanrahan, B. 1986. Simplistic CP fertilization facts. Carniv. Pl. Newslett. 15: 53. \\ Rice, B. 2003. Sarracenia distribution program. Carniv. Pl. Newslett. 32: 4-7. \\ Rice, B. 2006. Growing Carnivorous Plants. Timber Press, Portland.
}

